\title{
Efficacy evaluation of photodynamic therapy for oral lichen planus: a systematic review and meta-analysis
}

\author{
Yuqing $\mathrm{He}^{\dagger}$, Jiaxin Deng ${ }^{\dagger}$, Yi Zhao, Huiqian Tao, Hongxia Dan, Hao Xu ${ }^{*}$ (D) and Qianming Chen
}

\begin{abstract}
Background: Photodynamic therapy (PDT) is a new option for oral lichen planus (OLP) management; however, there are different opinions on the efficacy of PDT for OLP. The aim of this study was to comprehensively assess the efficacy of PDT in the treatment of OLP and compare PDT with steroid therapy.

Methods: A systematic review and meta-analysis were conducted to assess the curative effect of PDT. Five electronic databases were searched, PubMed, Web of Science, the Cochrane Library, Embase, and EBSCO up to 1 December, 2019. Random and fixed effects models for pooled estimates calculation were used and the Meta package of $\mathrm{R}$ was applied.

Results: Pooled estimates revealed that, after PDT, the lesion size decreased by $1.53 \mathrm{~cm}^{2}$ ( $95 \%$ confidence interval (Cl): 0.71-2.35) after PDT and the partial response (PR) was 0.77 (95\% Cl: 0.65-0.85). The visual analogue scale (VAS) score decreased by 3.82 (95\% Cl: 2.80-4.85) and the Thongprasom sign score decreased by 1.33 (95\% Cl: 0.56-2.10) after PDT. Subgroup analyses revealed that the 5-aminolevulinic acid (5-ALA) was more effective than methylene blue (MB), with a PR of 0.87 (95\% Cl: 0.80-0.91). The topical use of 5-ALA yielded a better response than gargling methylene blue. In terms of VAS, the diode laser showed a better clinical PR in the treatment of OLP. In terms of changes in lesion size, the efficacy of the semiconductor laser was higher than that of the diode laser. PDT had a similar efficacy to topical corticosteroids, as shown by pooled estimates of five randomised controlled trials with 139 lesions.
\end{abstract}

Conclusion: This systematic review indicates that PDT is an effective treatment modality for the management of OLP. PDT is as effective as topical corticosteroid in the treatment of OLP and could be used for cases resistant to steroids or when steroids are contraindicated.

Keywords: Photodynamic therapy, Oral lichen planus, Efficacy evaluation, Meta-analysis

\footnotetext{
* Correspondence: xhstatis@hotmail.com

†Yuqing He and Jiaxin Deng contributed equally to this work.

State Key Laboratory of Oral Diseases, National Clinical Research Center for Oral Diseases, Chinese Academy of Medical Sciences Research Unit of Oral Carcinogenesis and Management, West China Hospital of Stomatology, Sichuan University, No. 14, Sec.3, Ren Min Nan Road, Chengdu 610041, Sichuan, China
}

(c) The Author(s). 2020 Open Access This article is licensed under a Creative Commons Attribution 4.0 International License, which permits use, sharing, adaptation, distribution and reproduction in any medium or format, as long as you give appropriate credit to the original author(s) and the source, provide a link to the Creative Commons licence, and indicate if changes were made. The images or other third party material in this article are included in the article's Creative Commons licence, unless indicated otherwise in a credit line to the material. If material is not included in the article's Creative Commons licence and your intended use is not permitted by statutory regulation or exceeds the permitted use, you will need to obtain permission directly from the copyright holder. To view a copy of this licence, visit http://creativecommons.org/licenses/by/4.0/. The Creative Commons Public Domain Dedication waiver (http://creativecommons.org/publicdomain/zero/1.0/) applies to the data made available in this article, unless otherwise stated in a credit line to the data. 


\section{Background}

Oral lichen planus (OLP), a chronic immune-mediated, inflammatory, and psychosomatic condition that frequently affects the oral mucosa in a typical bilateral pattern, often presents as pain and a burning sensation [1]. OLP has an overall prevalence of about 2.2\% [2]. The most common is the reticular type, which has a white lacy appearance. Other forms include erosive, atrophic, bullous, papular, and plaque-like. OLP is an oral potentially malignant disorder (OPMD) and has been linked to oral squamous cell carcinoma with a malignant transformation rate of $1.4 \%$ [3].

The aim of OLP management is to reduce the occurrence of symptoms and manifestation of lesions. Currently, the most common treatment for OLP is pharmacological therapy. Others include surgery, photodynamic therapy, and laser therapy. There is a large difference in the curative effect of the current treatments. In pharmacologic therapy, topical corticosteroids are usually prescribed, such as triamcinolone acetonide and dexamethasone [4]. However, long-term treatment with topical corticosteroids may cause obvious side effects, such as local pigmentation, oral candidiasis, and dry mouth [5]. Additionally, some studies have claimed that patients do not respond to drug treatment and the erosion does not heal, which increases the risk of canceration [6].

Photodynamic therapy (PDT) is a therapeutic method based on the photochemical and photobiological effects that are mediated by a photosensitiser (PS), which leads to cell damage at the lesioned tissue [7]. It is a minimally invasive treatment because it has the advantage of high selectivity. Thus, PDT causes only mild trauma and adverse reactions and is a new option for the treatment of OLP.

Currently, there are different opinions on the efficacy of PDT for OLP. One study has revealed that PDT has some effect in the symptomatic treatment of OLP in adult patients [8]. However, the authors used a small number of articles and did not perform subgroup analyses. On the contrary, according to a systematic review [9], PDT fails to exert any significant effect on the symptoms of OLP. A meta-analysis that reviewed 22 publications has shown that the partial response (PR) rate of OLP lesions to PDT is approximately 70\%; however, this study analysed the effect of PDT on OPMD. Only six articles focused on OLP and the authors did not investigate the effect of different factors on the efficacy of PDT in OLP versus that in all OPMDs in the subgroup analysis [10].

These three reviews used a small number of articles focused on OLP and did not analyse the influence of factors, including the site of OLP lesion in mouth, type of PS, and administration method, that may be related to the final therapeutic response. Therefore, the aim of this systematic review and meta-analysis was to assess the efficacy of PDT in the treatment of OLP and compare the efficacy of PDT with steroid therapy. The results of this study will provide clinicians with a comprehensive understanding of the efficacy of PDT in OLP.

\section{Methods \\ Study identification and selection criteria}

The systematic review and meta-analysis were performed in accordance with the PRISMA statement [11], as detailed in Additional file 1: Table S1. This study has been registered on the International Prospective Register of Systematic Reviews (PROSPERO) under the registration number CRD42020160512.

Electronic and manual literature searches were conducted in the following five electronic databases: PubMed, Web of Science, the Cochrane Library, Embase, and EBSCO up to 1 December, 2019. Search terms were: "Photodynamic therapy" OR "PDT" AND "lichen planus" OR "oral lichen planus" OR "OLP."

The inclusion criteria were: (a) original articles, clinical studies, and case series; (b) aim of the intervention was to evaluate the efficacy of PDT in the management of OLP; (c) lesion response was assessed and recorded; (d) articles published only in the English language; (e) clinical or histopathological diagnosis of OLP. The PICO questions below were applied:

Population (P): patients were diagnosed as OLP;

Intervention (I): patients were treated with PDT;

Comparison (C): condition of patients before PDT or topical corticosteroids;

Outcome $(\mathrm{O})$ : lesion response and lesion size of patients with OLP.

The exclusion criteria were: (a) reviews, abstracts, commentaries, letters to the editor, opinion articles, and animal studies; (b) inconsistent efficacy evaluation standard such that subsequent analysis cannot be performed; (c) individuals with idiopathic plaque-like lichen planus (non-erosive), lichenoid drug eruptions, or evidence of dysplasia in the tissue.

\section{Data extraction}

Two authors (Z.Y. and D.J.X.) independently searched these five databases and assessed the titles and abstracts of all eligible publications. Details, including first author's name, publication year, type of PS, disease types, method of administration, disease location, and number of lesions, were collected from the included studies. Four outcome measures were collected for the efficacy evaluation: (a) lesion response, including complete response (CR), which means lack of visible lesion confirmed by clinical evaluation, and PR, which means lesion size decreased by at least 20\%; (b) changes in lesion size/area; (c) Thongprasom sign (TH): score of 0 for normal healthy mucosa, 1 for lesions with only white striae, 2 for mixed keratotic and atrophic or erythematous lesions 
smaller than $1 \mathrm{~cm}^{2}, 3$ for keratotic and atrophic or erythematous lesions larger than $1 \mathrm{~cm}^{2}, 4$ for erosive/ulcerative lesions smaller than $1 \mathrm{~cm}^{2}$, and 5 for erosive/ulcerative lesions larger than $1 \mathrm{~cm}^{2}$; (d) visual analogue scale (VAS) rated by participants (score: $0-10$ ): 0 means no symptoms and 10 means severe symptoms, as perceived by the patient.

Other parameters used for qualitative synthesis included wavelength, energy density of the laser, duration of irradiation, lesion dressing, treatment interval, relapse during follow-up, and adverse reactions during and after PDT.

\section{Quality assessment}

The included randomised controlled trials (RCTs) were assessed by the Cochrane Collaboration's risk of bias assessment tool, with seven fields: random sequence generation, allocation concealment, blinding of participants and personnel, blinding of outcome assessment, incomplete outcome data, selective reporting, and other bias [12]. The included non-RCTs were assessed by the Downs-Black Checklist, with 29 items [13]. The quality assessment was independently performed by two authors (H.Y.Q. and D.J.X.). Any conflicts were fully discussed and the corresponding authors (X.H. and C.Q.M.) would make the final decision.

\section{Statistical analysis}

The $I^{2}$ statistic and heterogeneity statistic $Q$ were calculated to assess heterogeneity and the random effect model was utilised to assess heterogeneity when the $I^{2}$ statistic was more than $50 \%$ or the $p$ value of the $Q$ test was less than 0.05 .

The outcome measures in this study were VAS, TH, size, and response (PR and $\mathrm{CR}$ ). The weighted mean differences of the first three continuous indexes were pooled by the inverse variance method (for the fixed effects model) and restricted maximum-likelihood (for the random effects model). The proportion and odds ratio (OR) of the response were pooled by the inverse variance method (for the fixed effects model) and the DerSimonian-Laird method (for the random effects model).

Publication bias was evaluated using a funnel plot and weighted linear regression was used to test funnel plot asymmetry if the number of the studies was not less than 10. Publication bias could be ignored when the $p$ value was greater than 0.05 .

Sensitivity analysis was utilised in subgroup and influence analyses. The light source, type of PS, administration method, and lesion location were considered for subgroup analysis and the $u$ test was applied for the differential test between different subgroups. The influence analysis of the pooled estimates was conducted by the omission of one study at a time.
The Meta package of $\mathrm{R}$ software was applied for the analyses [14].

\section{Results}

Demographic characteristics of included studies

The literature selection process is shown in Fig. 1. By searching the databases, 418 studies were found and 1 additional record was identified by reviewing the reference list of related studies. By removing duplicate articles, 225 remained. After screening titles and abstracts, 205 records were excluded. Four full-text were excluded as one was case report and three articles were not English. After full-text screening, 16 studies were considered for qualitative assessment and 13 studies were included for quantitative synthesis [15-30].

All patients were older than 18 years. In 13 studies, 5 RCTs compared the efficacy of PDT with topical corticosteroids. One article clearly stated that patients with the reticular type were included and two articles included the erosive type. The remaining information is presented in Table 1 and Additional file 1: Table S2-S3.

\section{Quality assessment of included studies}

The results of the Cochrane Collaboration's risk of bias assessment and Downs-Black Checklist are shown in Additional file 1: Figure S1 and Additional file 1: Table S4. The included RCT studies had a low or unclear risk of bias and, owing to the wide difference in treatment method between PDT and topical corticosteroids, most did not specify blinding (Additional file 1: Figure S1). The majority of non-RCT studies were of high quality in five fields: study quality, external validity, study bias, confounding effects, and power of the study (Additional file 1: Table S4).

\section{Data synthesis}

Lesion response

Ten publications involving 309 lesions assessed the lesion response (CR and PR) after PDT, the details of which are shown in Table 1.

As the recognition criteria for CR was strict, half of the studies had no CR and the pooled proportion of $C R$ by the random effects model (Additional file 1: Figure S2 shows the heterogeneity) was 0.08 , which indicated that only $8 \%$ of the lesions reached a CR. No publication bias existed (Additional file 1: Figure S3) and the sensitivity analysis showed that the results were relatively robust (Additional file 1: Figure S4).

The PRs are shown in Fig. 2. As heterogeneity was detected by the $Q$ test $(p$ value $<0.05)$ and $I^{2}$ statistic (71\%), the random effects model was applied to pool the overall proportion of PR, which was 0.77 (95\% CI: $0.65-$ 0.85 ). The funnel plot indicated that no publication bias existed (Additional file 1: Figure S5) and the robustness 


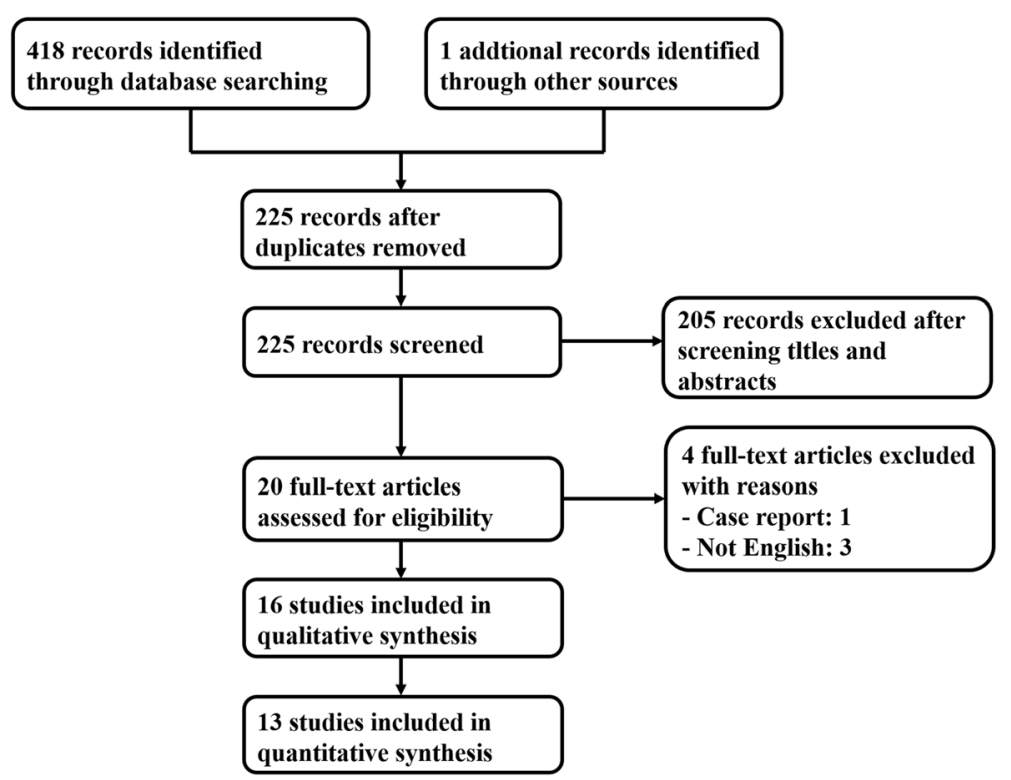

Fig. 1 Flow diagram of study selection

of the results was also validated by sensitivity analysis (Additional file 1: Figure S6).

To examine the influence of factors on the final therapeutic response of PDT, subgroup analyses were performed.

Light sources Five types of light source were utilised in 10 studies, including diode laser (three trials), xenon lamp (one trial), semiconductor laser (one trial), metal halide lamp (one trial), and light-emitting diode (LED) (four trials). As the standard of CR was so strict that half of the included studies achieved no CR, we only applied subgroup analysis for the PR. The forest plots of the different light sources are shown in Additional file 1: Figure S7 and Fig. 3a shows the results of the random effects model for the pooled PR. No significant difference (tested by $u$ test, $p>0.05$ ) was detected in the PR among light sources.

Ps Three types of PS were discussed in the studies, 5ALA (four trials), MB (five trials), and chlorin e6 derivative (one trial). The pooled PR of 5-ALA was 0.86 (95\% CI: $0.80-0.91$ ), which was more effective than other two and the difference was significant $(p<0.05)$ compared to MB (Fig. 3b and Additional file 1: Figure S8).

Administration methods Five trials used topical application and five used gargle administration. Topical application was more effective than the gargle method $(p<$ 0.05 ) and the pooled PR of topical application reached 0.85 (95\% CI: $0.80-0.89$ ) (Fig. $3 c$ and Additional file 1: Figure S9).

Additionally, two types of lesion locations (buccal mucosa and/or lips (BM/L) and tongue and/or gingival mucosa $(T / G)$, were detailed in three studies, including 194 lesions. The OR was calculated and pooled to compare the PR of the two lesion locations and the PDT would be regarded as more efficient in BM/L if the OR was greater than 1 . The PDT seemed to be more suitable for $\mathrm{BM} / \mathrm{L}$, although this was not statistically significant (pooled OR: 1.75, 95\% CI: 0.43-7.05) (Additional file 1: Figure S10).

\section{Changes of lesions}

The variables of lesion size and $\mathrm{TH}$ were included to assess the changes of the lesions after PDT.

The lesion size was recorded in six publications before and after PDT and 245 lesions were identified for metaanalysis. The lesion size decreased by $1.53 \mathrm{~cm}^{2}$ (95\%: 0.71-2.35) after PDT (Fig. 4a). Heterogeneity existed among the six studies, as the $\mathrm{I}^{2}$ statistic was $85 \%$ and the $p$ value of the $Q$ test was lower than 0.01 . The sensitivity analysis (Additional file 1: Figure S11) validated that the pooled estimates were stable. Publication bias could be ignored according to the funnel plot (Additional file 1: Figure S12).

Through subgroup analysis, lesion size decreased more using a semiconductor laser than using a diode laser (tested by $u$ test, $p<0.05$, Fig. $3 \mathrm{~d}$ ) and the lesions located on the BM/L decreased more than those located on the T/F/G (pooled MD: 0.37, 95\% CI: 0.05-0.68, Additional file 1: Figure S13), whereas no statistically significant differences were detected between PS and administration method (Fig. 3e and Fig. 3f).

To determine the $\mathrm{TH}$ score, five trials, including 88 lesions, were involved. Owing to the heterogeneity 
Table 1 Characteristics of the studies with lesion response and lesion size changes after PDT

\begin{tabular}{|c|c|c|c|c|c|c|c|c|c|c|c|c|c|}
\hline \multirow[t]{2}{*}{ Author } & \multirow[t]{2}{*}{ Year } & \multirow[t]{2}{*}{ Light sources } & \multirow[t]{2}{*}{ Photosensitizer } & \multirow[t]{2}{*}{$\begin{array}{l}\text { Lesion } \\
\text { types }\end{array}$} & \multirow[t]{2}{*}{$\begin{array}{l}\text { Administration } \\
\text { Method }\end{array}$} & \multirow[t]{2}{*}{$\begin{array}{l}\text { Lesion } \\
\text { locations }\end{array}$} & \multirow[t]{2}{*}{$\begin{array}{l}\text { Sample } \\
\text { size }\end{array}$} & \multirow[t]{2}{*}{ CR } & \multirow[t]{2}{*}{ PR } & \multicolumn{2}{|c|}{$\begin{array}{l}\text { lesion size } \\
\text { of pre-PDT }\end{array}$} & \multicolumn{2}{|c|}{$\begin{array}{l}\text { lesion size } \\
\text { of post-PDT }\end{array}$} \\
\hline & & & & & & & & & & Mean & $\overline{S D}$ & Mean & SD \\
\hline Aghahosseini F & 2006 & diode laser & $\mathrm{MB}$ & mixed & gargle & mixed & 26 & 4 & 12 & 1.8 & 0.7 & 1 & 0.9 \\
\hline Sadaksharam J & 2012 & xenon lamp & $M B$ & mixed & gargle & mixed & 20 & 0 & 10 & & & & \\
\hline \multirow[t]{3}{*}{ Sobaniec S } & 2013 & $\begin{array}{l}\text { semiconductor } \\
\text { laser }\end{array}$ & $\begin{array}{l}\text { chlorin e6 } \\
\text { derivative }\end{array}$ & mixed & topical & mixed & 48 & 14 & 25 & 6 & 4.5 & 2.7 & 2.62 \\
\hline & & & & & & $\mathrm{BM} / \mathrm{L}$ & 40 & 13 & 22 & 6.6 & 4.63 & 2.8 & 2.81 \\
\hline & & & & & & $T / G$ & 8 & 1 & 3 & 3 & 1.9 & 2.1 & 1.21 \\
\hline Prasanna SW & 2015 & $\begin{array}{l}\text { metal halide } \\
\text { lamp }\end{array}$ & $M B$ & mixed & gargle & mixed & 15 & 0 & 13 & 3 & 1.6 & 0.8 & 1 \\
\hline Maloth KN & 2016 & LED & 5-ALA & mixed & topical & mixed & 10 & 0 & 8 & 2.22 & 0.79 & 1.41 & 0.74 \\
\hline Bakhtiari S & 2017 & LED & $M B$ & mixed & gargle & mixed & 15 & 0 & 2 & & & & \\
\hline Mostafa D & 2017 & diode laser & $M B$ & mixed & gargle & mixed & 19 & 7 & 9 & & & & \\
\hline \multirow[t]{3}{*}{ Sulewska M } & 2017 & LED & 5-ALA & erosive & topical & mixed & 22 & 5 & 11 & 1.49 & 1.45 & 1.37 & 1.78 \\
\hline & & & & & & $\mathrm{BM}$ & 16 & 4 & 7 & 1.06 & 0.98 & 1.08 & 1.57 \\
\hline & & & & & & $\mathrm{T} / \mathrm{G}$ & 6 & 1 & 4 & 2.63 & 1.93 & 2.13 & 2.24 \\
\hline Rakesh N & 2018 & diode laser & 5-ALA & erosive & topical & mixed & 10 & 0 & 10 & & & & \\
\hline \multirow[t]{3}{*}{ Sulewska M } & 2019 & LED & 5-ALA & reticular & topical & mixed & 124 & 46 & 63 & 3.99 & 3.73 & 1.48 & 1.98 \\
\hline & & & & & & BM & 80 & 27 & 44 & 4.58 & 4.01 & 1.67 & 2.04 \\
\hline & & & & & & $\mathrm{T} / \mathrm{G}$ & 44 & 19 & 19 & 2.93 & 2.91 & 1.13 & 1.84 \\
\hline
\end{tabular}

PDT Photodynamic therapy, GaAlAs Gallium-Aluminum-Arsenide, LED Light emitting diode, TB Toluidine blue, 5-ALA 5 aminolevulinic acid, MB Methylene Blue, BM/ $L$ Buccal mucosa and/or lips, $T / G$ Tongue and/or gingival mucosa; mixed: with different required information or information were not mentioned, $C R$ Complete response, $P R$ Partial response, NR No response, SD Standard deviation

(Fig. 4b), the random effects model was recommended and the TH score decreased by 1.33 (95\% CI: 0.562.10) after PDT, which was validated for robustness with the sensitivity analysis (Additional file 1: Figure S14) and publication bias could be ignored (Additional file 1: Figure S15).

The subgroup analysis indicated that the metal halide lamp performed better than the LED and xenon lamp (Fig. 3g), whereas the PS and administration method showed no significant differences in performance (Fig. 3h and Fig. 3i).

\section{Clinical pain symptom}

The clinical pain symptom was measured by VAS and six studies with 88 lesions used VAS to assess the improvement of pain after PDT. The VAS score decreased by 3.82 (95\% CI: 2.80-4.85) (Fig. 4c).

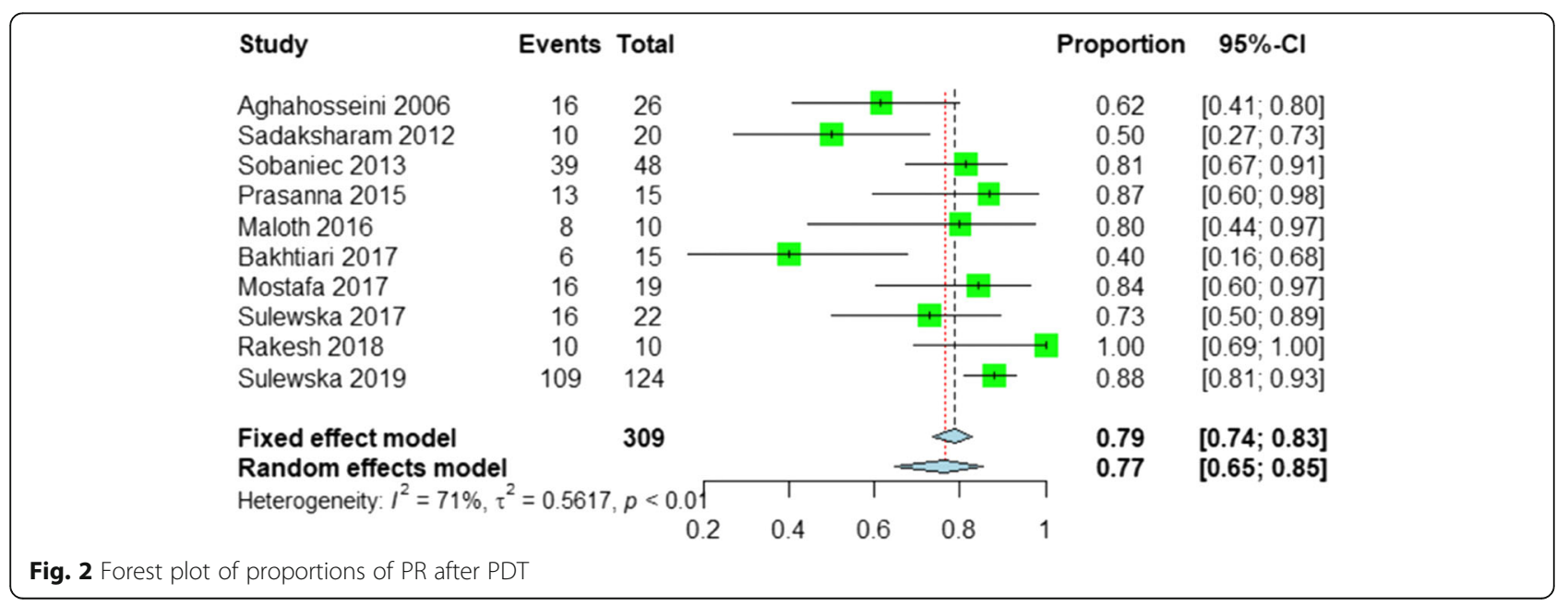




\section{A}

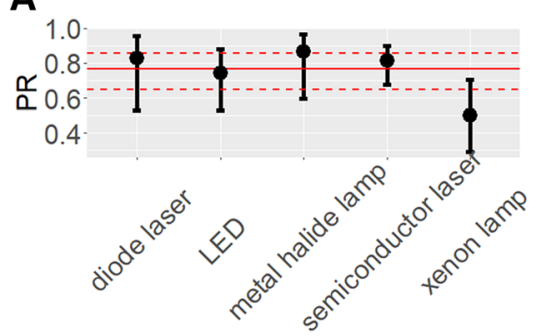

Light Source

D

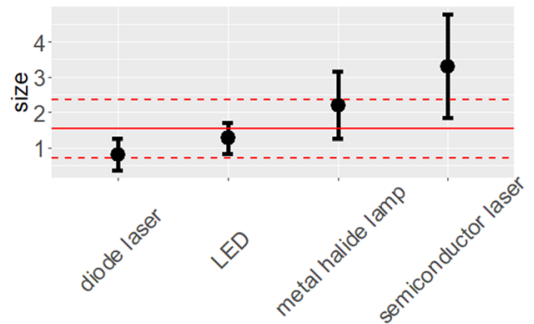

Light Source

$\mathbf{G}_{3}$

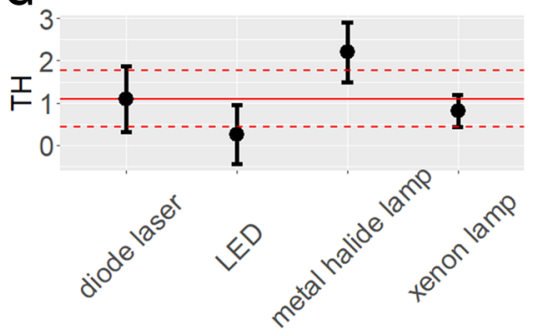

Light Source

J

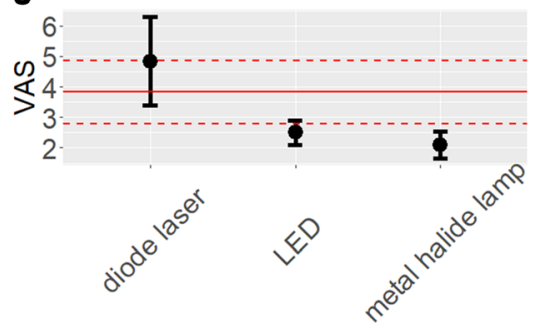

Light Source
B

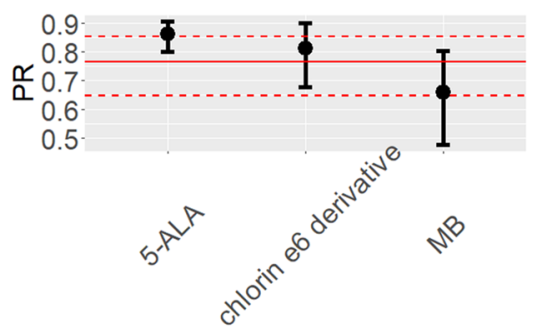

Photosensitizer

E

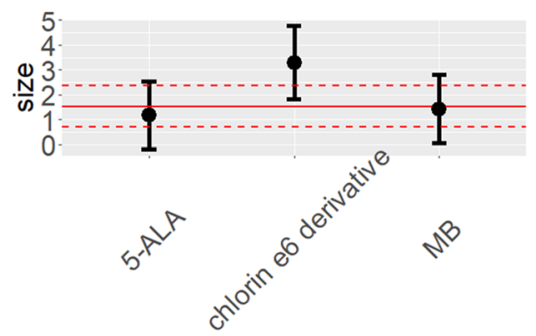

Photosensitizer

H

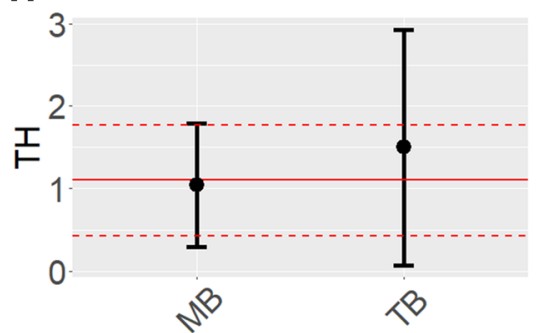

Photosensitizer

K

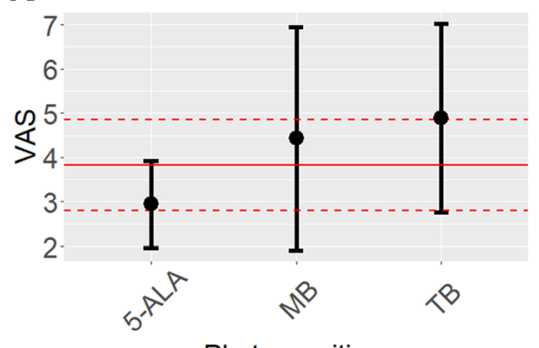

C

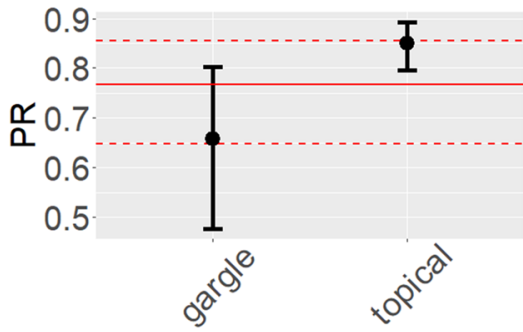

Administration Method

F

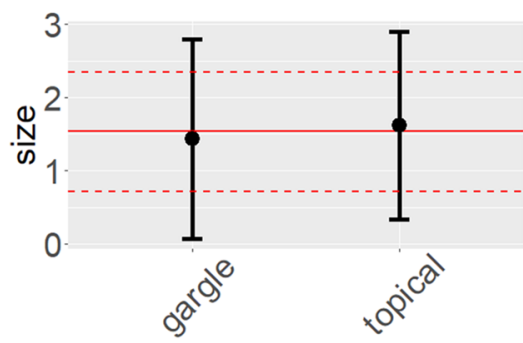

Administration Method

I

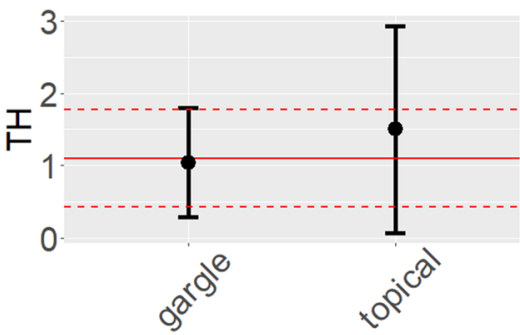

Administration Method

L

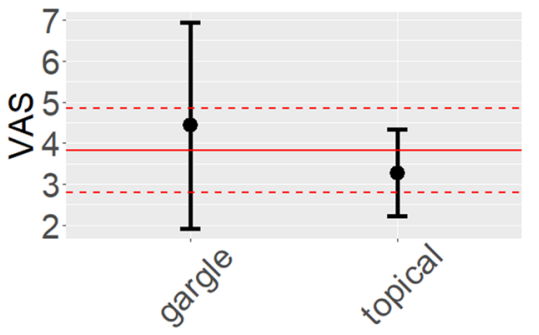

Administration Method

Fig. $\mathbf{3}$ a-j showed the results of subgroup analysis with random effects model, three factors were considered for subgroup analysis, namely, light sources $(\mathbf{a}, \mathbf{d}, \mathbf{g}, \mathbf{j})$, photosensitizers $(\mathbf{b}, \mathbf{e}, \mathbf{h}, \mathbf{k})$, administration methods $(\mathbf{c}, \mathbf{f}, \mathbf{i}, \mathbf{I})$. The three plots at the first column represent the results of PR, the plots at the second column represent the results of size, the plots at the third column represent the results of TH, the plots at the fourth column represent the results of VAS. The plots at the third column represent the results of VAS. The full red lines in the plots indicate the pooled overall estimates and the dashed red lines indicate the lower limits and upper limits of their $95 \% \mathrm{Cl}$

Heterogeneity existed ( $p$ value $<0.05$ and $I^{2}=92 \%$ ) and the result was robust (Additional file 1: Figure S16). Publication bias could be ignored according to the funnel plot (Additional file 1: Figure S17).

Unlike with lesion changes, the subgroup analysis revealed that the efficacy of the diode laser was better than that of the metal halide lamp and LED in relieving pain ( $u$ test $p<0.05$, Fig. $3 \mathrm{j})$. No differences were observed in the subgroup analysis of PS and administration method (Fig. 3k and Fig. 3l). Owing to the information shortage, the subgroup analysis of sites of OLP lesions was not performed. 

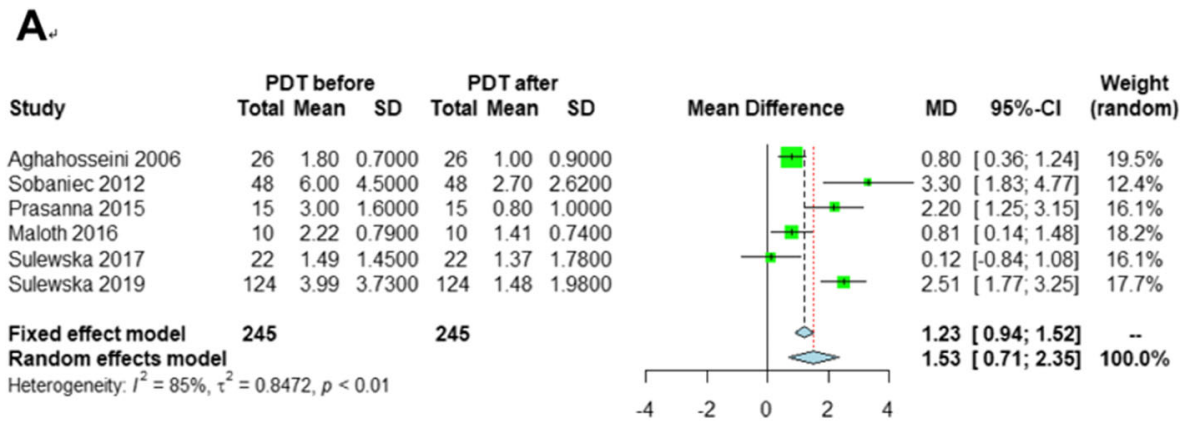

B.

\begin{tabular}{|c|c|c|c|c|c|c|}
\hline Study & \multicolumn{3}{|c|}{ PDT before } & \multicolumn{2}{|c|}{ PDT after } & SD \\
\hline Aghahosseini 2006 & 26 & 5.10 & 1.7000 & 26 & 0.90 & 1.5000 \\
\hline Prasanna 2015 & 15 & 2.50 & 0.5000 & 15 & 0.40 & 0.7000 \\
\hline Maloth 2016 & 10 & 2.70 & 0.4800 & 10 & 0.20 & 0.4200 \\
\hline Mostafa 2017 & 19 & 8.80 & 1.5500 & 19 & 1.50 & 3.1700 \\
\hline Rakesh 2018 & 10 & 6.20 & 1.0300 & 10 & 2.70 & 0.6700 \\
\hline Lavaee 2019 & 8 & 5.64 & 2.8380 & 8 & 0.75 & 1.1650 \\
\hline $\begin{array}{l}\text { Fixed effect model } \\
\text { Random effects model } \\
\text { Heterogeneity. } I^{2}=92 \%, \tau^{2}\end{array}$ & 88 & & & 88 & & \\
\hline
\end{tabular}

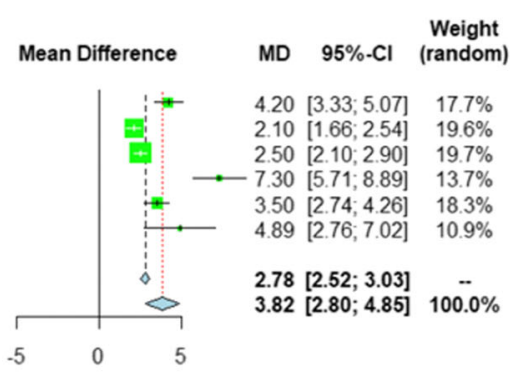

C.

\begin{tabular}{|c|c|c|c|c|c|c|}
\hline \multirow[b]{2}{*}{ Study } & \multicolumn{3}{|c|}{ PDT before } & \multicolumn{3}{|c|}{ PDT after } \\
\hline & Tota & Mean & SD & Tota & Mean & SD \\
\hline Aghahosseini 2006 & 26 & 3.35 & 1.8500 & 26 & 2.42 & 1.5500 \\
\hline Sadaksharam 2012 & 20 & 3.45 & 0.6900 & 20 & 2.64 & 0.5000 \\
\hline Prasanna 2015 & 15 & 3.20 & 0.7000 & 15 & 1.00 & 1.2000 \\
\hline Mostafa 2017 & 19 & 5.00 & 0.0000 & 19 & 1.84 & 1.8000 \\
\hline Lavaee 2019 & 8 & 4.00 & 1.1830 & 8 & 2.50 & 1.6900 \\
\hline $\begin{array}{l}\text { Fixed effect model } \\
\text { Random effects model } \\
\text { Heterogeneity: } I^{2}=75 \%, \tau^{2}\end{array}$ & 88 & & & 88 & & \\
\hline
\end{tabular}

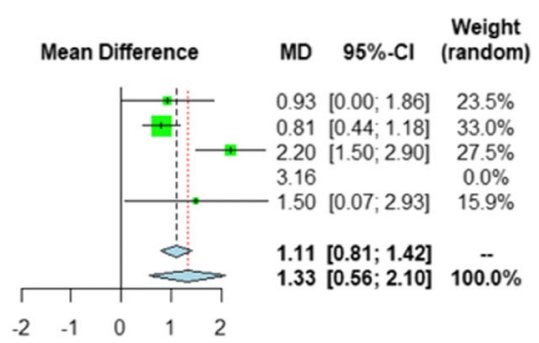

Fig. 4 Forest plots of mean difference between before and after PDT in three effect indicators. $\mathbf{a}$ : lesion size, $\mathbf{b}$ : TH score, $\mathbf{c}$ : VAS

\section{Comparison with topical corticosteroids}

To obtain an understanding of the efficacy of PDT, five RCT trials with 139 lesions were included to compare PDT with topical corticosteroids. The indicators included PR (recorded in two trials, 68 lesions in total), TH (recorded in four trials, 109 lesions in total), and VAS (recorded in four trials, 109 lesions in total), the details of which are shown in Additional file 1: Table S3. The pooled estimates indicated varied results. The efficacy of PDT was better than that of topical corticosteroids (pooled OR: 6.15, 95\% CI: 1.65-22.97) based on the on PR (Additional file 1: Figure S18). With the $\mathrm{TH}$ score (Additional file 1: Figure S19), the pooled mean difference was 0.62 (95\% CI: $-0.46-1.71$ ), which indicated that the two treatments had similar efficacy to decrease lesion size. Additionally, the pooled mean difference of
VAS (Additional file 1: Figure S20) was - 0.30 (95\% CI: -1.99-1.40), which indicated the similar improvement of pain between the two treatments.

\section{Other factors in PDT}

The wavelength of $630-660 \mathrm{~nm}$ and energy density of $80-150 \mathrm{~J} / \mathrm{cm}^{2}$ were commonly used. The duration of irradiation ranged between $120 \mathrm{~s}$ and $600 \mathrm{~s}$. The range of dressing time was 5-120 min. The frequency of PDT application ranged from 1 to 10 times throughout the study period at 1 - to 2 -week intervals. The details are shown in Table 2.

The majority of patients experienced no discomfort or only minor adverse effects (pain, mild burning sensation) during treatment, which disappeared immediately. Most studies were conducted with a usual follow-up time of 1-12 months. Among all studies, 
Table 2 Parameters without meta-analysis of the studies included

\begin{tabular}{|c|c|c|c|c|c|c|c|c|}
\hline Author & Year & Wavelength (nm) & $\begin{array}{l}\text { Energy density } \\
\left(\mathrm{J} / \mathrm{cm}^{2}\right)\end{array}$ & $\begin{array}{l}\text { Duration of } \\
\text { irradiation(s) }\end{array}$ & $\begin{array}{l}\text { Dressing time } \\
(\mathrm{min})\end{array}$ & $\begin{array}{l}\text { Frequency } \\
\text { of PDT }\end{array}$ & Recurrence & $\begin{array}{l}\text { Follow-up time } \\
\text { (month) }\end{array}$ \\
\hline Aghahosseini, F & 2006 & 632 & 120 & 120 & 5 & 1 session & NA & 3 \\
\hline Sadaksharam J & 2012 & $632 \pm 5$ & 120 & 1200 & 5 & 4 weekly & NA & 6 \\
\hline Sobaniec S & 2012 & 660 & 90 & NA & 60 & 2 weekly & NA & 5 \\
\hline Kvaal SI & 2013 & $600-660$ & 75 & NA & 60 & 1 session & 2 & $6-48$ \\
\hline Saleh WE & 2014 & 660 & 100-130 & 120 & 5 & 1 session & NA & 1 \\
\hline Jajarm HH & 2015 & 630 & 1.5 & 150 & 10 & Once 2-weeks & 0 & 1 \\
\hline Prasanna SW & 2015 & $630 \pm 10$ & 120 & NA & 5 & Once a week & NA & 3 \\
\hline Maloth KN & 2016 & 420 & 210 & 600 & 30 & 1 session & NA & 1 \\
\hline Bakhtiari S & 2017 & 630 & $7.2-14.4$ & 120 & 10 & NA & NA & 3 \\
\hline Mostafa D & 2017 & 660 & 100-130 & 70 & NA & Once a week & 0 & 2 \\
\hline Sulewska M & 2017 & 630 & 150 & 500 & 120 & 10 weekly & 4 & 12 \\
\hline Mirza S & 2018 & 630 & 1.5 & 150 & 10 & Twice a week & NA & 1 \\
\hline Paiziyeva Z & 2018 & 632.7 & NA & NA & NA & NA & NA & NA \\
\hline Rakesh N & 2018 & $600-670$ & 80 & NA & 120 & 1 session & 0 & 48 \\
\hline Lavaee F & 2019 & 660 & 19.23 & 600 & 10 & 3 sessions & NA & 2 \\
\hline Sulewska M & 2019 & 630 & 150 & 500 & 120 & 10 weekly & 0 & 12 \\
\hline
\end{tabular}

$\mathrm{nm}$ Nanometers, $\mathrm{J} / \mathrm{cm}^{2}$ Joules per square centimeters, NA Not available

six patients in two studies were reported to have relapsed after PDT. However, most studies did not report a cancerous patient.

\section{Discussion}

The pooled estimates of lesion response, changes in size, VAS, and TH revealed that PDT could not only reduce the lesion size but also reduce pain. PDT is a new noninvasive treatment that could be effective for the treatment of OLP.

The topical use of 5-ALA had a higher efficacy than gargling $\mathrm{MB}$ in terms of PR. The relatively poor outcome of $\mathrm{MB}$ could be owing to the short gargling time of 5 $\mathrm{min}$. The time of the topical use of 5-ALA can be 30-$120 \mathrm{~min}$. The longer the PS stays on the lesions, the better efficacy of PDT. Constant saliva secretion and frequent tissue movement may impair drug absorption. Thus, a high local concentration of PS may achieve better potency than the use of drugs. In four studies that used 5-ALA as the PS, the range of 5-ALA was $4-5 \%$. Therefore, the topical use of 5\% ALA may be recommended as the optimal modality.

When 5\% ALA is used a wavelength of $630 \mathrm{~nm}$ is recommended because $635 \mathrm{~nm}$ corresponds to the absorption peak of 5-ALA. In studies that involve gargling MB, the chosen wavelength of $632-660 \mathrm{~nm}$ did not reach the maximum absorption wavelength of MB (around 665 $\mathrm{nm}$ ), which also partially explains why the effect of $\mathrm{MB}$ was less than that of 5-ALA. Therefore, it is important to choose a suitable wavelength for PS.

In terms of VAS, the diode laser showed a better clinical PR in the treatment of OLP, perhaps because it emits only one wavelength of light. Thus, we recommend the diode laser as the first option to relieve pain. However, to change lesion size, the efficacy of the semiconductor laser was higher than that of the diode laser.

Some scholars [26] have supported the hypothesis that PDT stimulates healing processes, which become more evident during long-term observation, particularly within the masticatory mucosa. This tentative hypothesis needs to be confirmed by a greater number of cured cases. In the study of Sulewska et al. [23], the mean lesion size reduction was $62.91 \%$, which was significant, after PDT, showing a slightly higher value for the lesions on the $\mathrm{BM} / \mathrm{L}(63.54 \%)$ than on the T/G (61.43\%), whereas in our study, the effect of PDT on the lesions on the BM/L and $\mathrm{T} / \mathrm{F} / \mathrm{G}$ was similar.

A previous study has compared the apoptosis level in reticular and erosive OLP showed significantly more apoptosis and a markedly lower thickness of the oral epithelium in the erosive type than in the reticular type, which indicated more inflammation and cell destruction in erosive OLP than in reticular OLP [31]. PS tends to accumulate in abnormal hyperplasia and tumour tissue and some researchers believe that this may be related to a defect in the cell membrane structure. We speculated that the PDT of erosive OLP is more effective than that 
of reticular OLP. However, the subgroup analysis of disease type in our study showed no statistical significance based on the $u$ test, possibly because two studies were included for erosive OLP and only one for reticular OLP.

The PDT of OLP resulted in fewer adverse reactions. The majority of patients experienced no discomfort or only minor adverse effects (pain, mild burning sensation) during treatment, which disappeared immediately.

Currently, the recurrence rate of OLP after PDT is unknown but one feature of OLP is easy recurrence. Among all studies, six patients in two studies experience OLP recurrence after PDT but three studies reported no recurrence in 1-12 months follow-up. OLP is a chronic disease; thus, the follow-up periods need to be longer to reliably determine recurrence rates after PDT. PDT can reduce the risk of malignant transformation. One study has revealed that the malignant transformation rate of OLP is $1.4 \%$; however, the studies in this review did not record this rate [3]. Thus, the long-term effects of PDT remain unclear and there is an urgent need to carry out large sample, multi-centre, clinical research to explore and verify the factors that influence the efficacy of PDT.

Presently, the most common treatment for OLP is topical corticosteroids [4]. We compared the efficacy of PDT to topical corticosteroids. A similar efficacy was observed between PDT and corticosteroid therapy. PDT had fewer side effects than steroids. Therefore, PDT can be used as an optional treatment method for resistant or recurrent OLP.

A few weaknesses of this study need to be addressed in the future. An insufficient number of trials met the inclusion criteria, which reduced the significance of the results, especially in the subgroup analysis and comparison with topical corticosteroids. The outcome measures varied in the different trials, which hindered data combination. Additionally, heterogeneity in some parameters, such as wavelength and energy density, may have led to low statistical power. Although these disadvantages existed in this study, the results still provide clinicians with a comprehensive view of the efficacy of PDT in OLP, although more high-quality clinical studies are required to improve the reliability of the results.

\section{Conclusions}

PDT could be a valuable optional treatment for the management of OLP. The overall PR could reach 0.75 and the topical use of 5\% ALA could be the optimal PS. These results indicated that the curative effect of PDT is similar to that of topical corticosteroids in the treatment of OLP.

\section{Supplementary information}

Supplementary information accompanies this paper at https://doi.org/10. 1186/s12903-020-01260-x.

Additional file 1: Appendix Table S1. PRISMA checklist. Appendix Table S2. Characteristics of the 16 studies included for qualitative assessment. Appendix Table S3. Results of bias risk assessment for each included non-RCT (score). Appendix Table S4. Characteristics of the studies with VAS and TH changes after treatment. Appendix Figure S1. Risk of bias summary: review authors' judgments about each risk of bias items for each included RCT. Appendix Figure S2. Forest plot of CR after PDT. Appendix Figure S3. Funnel plot of CR after PDT. Appendix Figure S4. Sensitivity analysis for CR after PDT. Appendix Figure S5. Funnel plot of PR after PDT. Appendix Figure S6. Sensitivity analysis for PR after PDT. Appendix Figure S7. Forest plots of PR after PDT: subgroup analysis of light sources. Appendix Figure S8. Forest plots of PR after PDT: subgroup analysis of photosensitizers. Appendix Figure S9. Forest plots of PR after PDT: subgroup analysis of administration methods. Appendix Figure S10. Forest plot of PR after PDT: subgroup analysis of lesion locations. Appendix Figure S11. Sensitivity analysis for the changes of lesion size. Appendix Figure S12. Funnel plot for lesion size after PDT. Appendix Figure S13. Forest plot of size after PDT: subgroup analysis of lesion location. Appendix Figure S14. Sensitivity analysis for the results of TH. Appendix Figure S15. Funnel plot for TH after PDT. Appendix Figure S16. Sensitivity analysis for the results of VAS. Appendix Figure S17. Funnel plot for VAS after PDT. Appendix Figure S18. Forest plot of PDT comparing with topical corticosteroids on PR. Appendix Figure S19. Forest plot of PDT comparing with topical corticosteroids on TH. Appendix Figure S20. Forest plot of PDT comparing with topical corticosteroids on VAS.

\section{Abbreviations}

5-ALA: 5-aminolevulinic acid; BM/L: Buccal mucosa and/or lips; $\mathrm{Cl}$ : Confidence interval; CR: Complete response; LED: Light-emitting diode; MB: Methylene blue; OLP: Oral lichen planus; OPMD: Oral potentially malignant disorder; OR: Odds ratio; PDT: Photodynamic therapy; PR: Partial response; PROSPERO: Prospective Register of Systematic Reviews; PS: Photosensitiser; RCT: Randomised controlled trial; T/G: Tongue and/or gingival mucosa; TH: Thongprasom sign; VAS: Visual analogue scale

\section{Acknowledgments}

Not applicable.

\section{Authors' contributions}

Dr. X.H. and Prof. C.Q.M. had full access to all the data in the study and takes responsibility for the integrity of the data and the accuracy of the data analysis. Concept and design: H.Y.Q., X.H. Acquisition, analysis, or interpretation of data: All authors. Drafting of the manuscript: H.Y.Q., X.H. Critical revision of the manuscript for important intellectual content: All authors. Statistical analysis: H.Y.Q., D.J.X. Administrative, technical, or material support: X.H. The author(s) read and approved the final manuscript.

\section{Funding}

The authors gratefully acknowledge support received from the National Natural Science Foundation of China (81730030, U19A2005, 81771081, 81572663), the 111 Project of MOE (B14038), Sichuan University Postdoctoral Research Foundation (19XJ0008).

Availability of data and materials

All data generated or analysed during this study are included in this published article.

Ethics approval and consent to participate

Not applicable.

Consent for publication

Not applicable.

Competing interests

The authors declare that they have no competing interests. 
Received: 4 March 2020 Accepted: 22 September 2020

Published online: 04 November 2020

\section{References}

1. Panta P, Andhavarapu A, Patil S. A holistic intervention for Oral lichen Planus. J Contemp Dent Pract. 2019;20(7):765-7.

2. Cheng Y-SL, Gould A, Kurago Z, Fantasia J, Muller S. Diagnosis of oral lichen planus: a position paper of the American Academy of Oral and maxillofacial pathology. Oral Surg Oral Med Oral Pathol Oral Radiol. 2016;122(3):332-54.

3. Richards D. Malignant transformation rates in Oral lichen Planus. Evid-Based Dentistry. 2018;19(4):122.

4. Oberti L, Alberta L, Massimo P, Francesco C, Dorina L. Clinical Management of Oral Lichen Planus: a systematic review. Mini-Rev Med Chem. 2019;19(13): 1049-59.

5. Amanat D, Ebrahimi H, Zahedani MZ, Zeini N, Pourshahidi S, Ranjbar Z. Comparing the effects of cryotherapy with nitrous oxide gas versus topical corticosteroids in the treatment of oral lichen planus. Indian J Dental Res. 2014;25(6):711.

6. Bornstein MM, Kalas L, Lemp S, Altermatt HJ, Rees TD, Buser D. Oral lichen planus and malignant transformation: a retrospective follow-up study of clinical and histopathologic data. Quintessence Int. 2006:37(4):261-71.

7. Chen Q, Dan H, Tang F, Wang J, Li X, Cheng J, et al. Photodynamic therapy guidelines for the management of oral leucoplakia. Int J Oral Sci. 2019;11(2):1-5.

8. Akram Z, Javed F, Hosein M, Al-Qahtani MA, Alshehri F, Alzahrani Al, et al. Photodynamic therapy in the treatment of symptomatic oral lichen planus: a systematic review. Photodermatol Photoimmunol Photomed. 2018;34(3): 167-74.

9. Jajarm HH, Asadi R, Bardideh E, Shafaee H, Khazaei Y, Emadzadeh M. The effects of photodynamic and low-level laser therapy for treatment of oral lichen planus - a systematic review and meta-analysis. Photodiagn Photodyn Ther. 2018:23:254-60.

10. Jin $X, X u$ H, Deng J, Dan H, Ji P, Chen Q, et al. Photodynamic therapy for oral potentially malignant disorders. Photodiagn Photodyn Ther. 2019;28:146.

11. Shamseer L, Moher D, Clarke M, Ghersi D, Liberati A, Petticrew M, et al. Preferred reporting items for systematic review and meta-analysis protocols (PRISMA-P) 2015: elaboration and explanation. BMJ. 2015;349(1):g7647.

12. Higgins JP, Altman DG, Gøtzsche PC, Jüni $P$, Moher D, Oxman AD, et al. The Cochrane Collaboration's tool for assessing risk of bias in randomised trials. Bmj. 2011;343:d5928.

13. Downs SH, Black N. The feasibility of creating a checklist for the assessment of the methodological quality both of randomised and non-randomised studies of health care interventions. J Epidemiol Community Health. 1998; 52(6):377-84.

14. Schwarzer G. Meta: an R package for meta-analysis. R News. 2007;7(3):40-5

15. Bakhtiari S, Azari-Marhabi S, Mojahedi SM, Namdari M, Rankohi ZE, Jafari S. Comparing clinical effects of photodynamic therapy as a novel method with topical corticosteroid for treatment of Oral lichen Planus. Photodiagn Photodyn Ther. 2017;20:159-64.

16. Mostafa D, Moussa E, Alnouaem M. Evaluation of photodynamic therapy in treatment of oral erosive lichen planus in comparison with topically applied corticosteroids. Photodiagn Photodyn Ther. 2017;19:56-66.

17. Aghahosseini F, Arbabi-Kalati F, Fashtami LA, Djavid GE, Fateh M, Beitollahi JM. Methylene blue-mediated photodynamic therapy: a possible alternative treatment for oral lichen planus. Lasers Surg Med. 2006;38(1):33-8.

18. Sadaksharam J, Nayaki KT, Panneer Selvam N. Treatment of oral lichen planus with methylene blue mediated photodynamic therapy - a clinical study. Photodermatol Photoimmunol Photomed. 2012;28(2):97-101.

19. Sobaniec S, Bernaczyk P, Pietruski J, Cholewa M, Skurska A, Dolińska E, et al. Clinical assessment of the efficacy of photodynamic therapy in the treatment of oral lichen planus. Lasers Med Sci. 2012;28(1):311-6.

20. Kvaal SI, Angell-Petersen E, Warloe T. Photodynamic treatment of oral lichen planus. Oral Surg Oral Med Oral Pathol Oral Radiol. 2013;115(1):62-70.

21. Saleh WE, Khashaba O, El nagdy S, Moustafa MD. Photodynamic therapy of Oral erosive lichen Planus in diabetic and hypertensive patients. Mansoura J Dentistry. 2014;1(3):119-23.

22. Lavaee F, Shadmanpour M. Comparison of the effect of photodynamic therapy and topical corticosteroid on oral lichen planus lesions. Oral Dis. 2019;25(8):1954.
23. Sulewska M, Duraj E, Sobaniec S, Graczyk A, Milewski R, Wroblewska M, et al. A clinical evaluation of efficacy of photodynamic therapy in treatment of reticular oral lichen planus: a case series. Photodiagn Photodyn Ther. 2019; 25:50-7.

24. Maloth KN, Velpula N, Kodangal S, Sangmesh M, Vellamchetla K, Ugrappa S, et al. Photodynamic therapy - a non-invasive treatment modality for precancerous lesions. J Lasers Med Sci. 2016;7(1):30-6.

25. Prasanna SW, Ingle E, Aruna PR, Pravada C, Koteeswaran D, Ganesan S. Photodynamic therapy of oral leukoplakia and oral lichen planus using methylene blue: a pilot study. J Innovative Optical Health Sci. 2015;08:01.

26. Sulewska M, Duraj E, Sobaniec S, Graczyk A, Milewski R, Wroblewska M, et al. A clinical evaluation of the efficacy of photodynamic therapy in the treatment of erosive oral lichen planus: a case series. Photodiagn Photodyn Ther. 2017;18:12-9.

27. Mirza S, Rehman N, Alrahlah A, Alamri WR, Vohra F. Efficacy of photodynamic therapy or low level laser therapy against steroid therapy in the treatment of erosive-atrophic oral lichen planus. Photodiagn Photodyn Ther. 2018;21:404-8.

28. Jajarm HH, Falaki F, Sanatkhani M, Ahmadzadeh M, Ahrari F, Shafaee H. A comparative study of toluidine blue-mediated photodynamic therapy versus topical corticosteroids in the treatment of erosive-atrophic oral lichen planus: a randomized clinical controlled trial. Lasers Med Sci. 2015;30(5): 1475-80.

29. Rakesh N, Clint JB, Reddy SS, Nagi R, Chauhan P, Sharma S, et al. Clinical evaluation of photodynamic therapy for the treatment of refractory oral lichen planus - a case series. Photodiagn Photodyn Ther. 2018:24:280-5.

30. Paiziyeva Z, Puriene A. The effectiveness of the combined use of a polysaccharide film with photodynamic action in complex therapy of oral lichen planus in the oral cavity. Drug Invention Today. 2018;10:12.

31. Brant JMC, Vasconcelos AC, Rodrigues LV. Role of apoptosis in erosive and reticular oral lichen planus exhibiting variable epithelial thickness. Braz Dent J. 2008;19(3):179-85.

\section{Publisher's Note}

Springer Nature remains neutral with regard to jurisdictional claims in published maps and institutional affiliations.

Ready to submit your research? Choose BMC and benefit from:

- fast, convenient online submission

- thorough peer review by experienced researchers in your field

- rapid publication on acceptance

- support for research data, including large and complex data types

- gold Open Access which fosters wider collaboration and increased citations

- maximum visibility for your research: over $100 \mathrm{M}$ website views per year

At $\mathrm{BMC}$, research is always in progress.

Learn more biomedcentral.com/submission 